\section{Comparação entre diversos métodos de contagem diferencial de leucócitos em pacientes leucopênicos}

\section{Comparison between different methods of differential counting of leukocytes in leukopenia patients}

Alessandra P. Santos ${ }^{1}$

Mateus B. Bandeira ${ }^{2}$

Luciano O. Siqueira ${ }^{3}$

${ }^{1}$ Farmacêutica-Bioquímica. Aluna do Curso de Especialização em Hematologia e Hemoterapia da Universidade de Passo Fundo-RS. ${ }^{2}$ Aluno do Curso de Farmácia da Universidade de Passo Fundo-RS. ${ }^{3}$ Farmacêutico-Bioquímico. Professor do Curso de Farmácia da Universidade de Passo Fundo. Coordenador do Curso de Pós-graduação em Hematologia e Hemoterapia da Universidade de Passo Fundo-RS.

\section{Senhor Editor}

A leucopenia é caracterizada pela diminuição do número de leucócitos abaixo de $4.0 \times 10^{9} / \mathrm{L}$, sendo que os quadros de imunossupressão (neutrófilos $<0.5 \times 10^{9} / \mathrm{L}$ ), tornam o paciente leucopênico mais vulnerável a infecções oportunistas. ${ }^{1-4}$ Assim, é fundamental que o paciente leucopênico seja submetido a uma avaliação laboratorial rápida e fidedigna.

A contagem eletrônica de células é obtida em contadores hematológicos automatizados, fornecendo resultados sensíveis, reprodutíveis e precisos. ${ }^{5}$ No entanto, algumas amostras analisadas necessitam avaliação microscópica da distensão sanguínea para observação de anormalidades morfológicas, que podem ser significativas e relevantes. ${ }^{6} \mathrm{O}$ método de concentração de leucócitos (Buffy coat) consiste em concentrar os elementos celulares mais raros, facilitando a pesquisa de células anormais ou raras na população leucopênica. ${ }^{5,7}$

Partindo destes princípios, o objetivo deste estudo foi analisar diferentes metodologias para a contagem diferencial de leucócitos em pacientes leucopênicos, comparando o método de concentrado de leucócitos frente aos métodos comumente utilizados, como contagem eletrônica de células e análise da distensão sanguínea corada em microscopia convencional.

As amostras de sangue cuja leucometria apresentouse inferior a $4.0 \times 10^{9} / \mathrm{L}$ na contagem eletrônica de células (Cell Dyn 3000®) foram separadas e imediatamente encaminhadas para processamento pelos métodos de contagem manual direta e concentrado de leucócitos.

Oitenta amostras de sangue com leucometria inferior a $4.0 \times 10^{9} / \mathrm{L}$ foram separadas em quatro grupos de vinte amostras acordo com a leucometria: G1 (<1.0 x 109/L), G2 $\left(1.0-1.9 \times 10^{9} / \mathrm{L}\right), \mathrm{G} 3\left(2.0-2.9 \times 10^{9} / \mathrm{L}\right), \mathrm{G} 4\left(3.0-3.9 \times 10^{9} / \mathrm{L}\right)$.

Os dados foram testados quanto à sua normalidade mediante análise de Kolmogorof-Smirnoff. A seguir, os resultados foram analisados estatisticamente pelo teste de correlação de Spearman para dados não paramétricos no pacote estatístico do SPSS 10.0, considerando $\mathrm{p}<0,05$ como nível mínimo de significância. A concordância entre variáveis categóricas foi testada através do coeficiente de concordância Kappa. Os resultados foram expressos em valores absolutos da correlação (r), onde "0" indica uma total ausência de correlação linear e "1" uma relação linear perfeita.

Os valores absolutos da correlação (r) das contagens absolutas pela microscopia convencional e camada de leucócitos mostraram boa correlação de neutrófilos e linfócitos e baixa correlação para eosinófilos, basófilos e monócitos, sendo que a contagem de basófilos apresentou diferença estatisticamente significativa $(\mathrm{p}<0,05)$ em pelo menos dois dos quatro grupos analisados. (Tabela 1).

Analisando a Tabela 2, observa-se a concordância de flags emitidos pelo equipamento Cell Dyn $3000 \AA$, quando

Tabela 1. Resultados dos valores absolutos da correlação ( $r$ ) para contagem absoluta de células (céls $\times 10^{9} / \mathrm{L}$ ) obtida pela microscopia convencional / versus distensão de concentrado de leucócitos (Buffy coat)

\begin{tabular}{cccccc}
\hline Leucometria & Segmentados/L & Eosinófilos/L & Basófilos/L & Linfócitos/L & Monócitos/L \\
\hline $\begin{array}{c}<1.0 \times 10^{9} / \mathrm{L} \\
(\mathrm{n}=20)\end{array}$ & 0,882 & 0,516 & 0,444 & 0,961 & 0,923 \\
$\begin{array}{c}1.0-1.9 \times 10^{9} / \mathrm{L} \\
(\mathrm{n}=20)\end{array}$ & 0,978 & 0,856 & $<0,0001$ & 0,971 & 0,774 \\
$\begin{array}{c}2.0-2.9 \times 10^{9} / \mathrm{L} \\
(\mathrm{n}=20)\end{array}$ & 0,882 & 0,628 & 0,169 & 0,857 & 0,577 \\
$\begin{array}{c}3.0-3.9 \times 10^{9} / \mathrm{L} \\
(n=20)\end{array}$ & 0,914 & 0,735 & $<0,0001$ & 0,899 & 0,665 \\
$\begin{array}{c}\text { Média dos } \\
\text { grupos }(n=80)\end{array}$ & 0,914 & 0,684 & 0,153 & 0,922 & 0,735 \\
\hline
\end{tabular}


Tabela 2. Confirmação dos flags emitidos pelo equipamento Cell Dyn 3000 comprovados pela microscopia

\begin{tabular}{ccccc}
\hline & \multicolumn{2}{c}{ Microscopia convencional } & \multicolumn{2}{c}{ Exame de camada de leucócitos } \\
\hline Flags & Concordantes & $\begin{array}{c}\text { Não } \\
\text { concordantes }\end{array}$ & Concordantes & $\begin{array}{c}\text { Não } \\
\text { concordantes }\end{array}$ \\
\hline $\begin{array}{c}\text { Neutrófilos jovens } \\
(\mathrm{n}=46)\end{array}$ & 7 & 39 & 10 & 36 \\
$\begin{array}{c}\text { Granulócitos imaturos } \\
(\mathrm{n}=38)\end{array}$ & $(15,22 \%)$ & $(84,78 \%)$ & $(21,74 \%)$ & $(78,26 \%)$ \\
$\begin{array}{c}\text { Blastos } \\
(\mathrm{n}=18)\end{array}$ & $(0 \%)$ & 38 & 6 & 32 \\
$\begin{array}{c}\text { Linfócitos Atípicos } \\
(\mathrm{n}=12)\end{array}$ & 4 & $(100 \%)$ & $(15,79 \%)$ & $(84,21 \%)$ \\
$\begin{array}{c}\text { Total de Flags } \\
(\mathrm{n}=114)\end{array}$ & $(22,22 \%)$ & $(77,78 \%)$ & $(38,88 \%)$ & 11 \\
& $(0 \%)$ & 12 & 0 & $(61,12 \%)$ \\
& 11 & $(100 \%)$ & $(0 \%)$ & 12 \\
& $(9,65 \%)$ & $(90,35 \%)$ & $(20,18 \%)$ & 91 \\
\end{tabular}

comparados com a análise da distensão sanguínea pela microscopia convencional e análise após concentração de leucócitos. Verifica-se que, após concentração, há um número superior de concordância de flags $(20,18 \%)$ em relação à microscopia convencional. Essa diferença pode ser justificada pela concentração de elementos raros na última metodologia, facilitando a observação desses elementos. Além disso, o concentrado de leucócitos permite a visualização de células raras, que poderiam passar despercebidas na contagem normal direta e que têm uma importância relevante para pacientes em tratamento quimioterápico que, porventura, possam apresentar um quadro de remissão hematológica.

A análise dos resultados mostra boa correlação de neutrófilos e linfócitos entre as diferentes metodologias, enquanto eosinófilos e basófilos apresentaram baixo índice de correlação. Na contagem manual direta, os valores obtidos proporcionam uma estimativa grosseira da frequência celular devido a maior quantidade de neutrófilos e linfócitos e menor quantidade de eosinófilos e basófilos. ${ }^{5}$

Monócitos também mostraram um baixo índice de correlação, provavelmente devido à distribuição irregular dessas células no esfregaço, em vista das diferenças de tamanho, gravidades específicas, aderências entre os tipos de leucócitos, sendo os monócitos concentrados nas margens e na cauda do esfregaço. ${ }^{5,6}$

Mesmo que a contagem eletrônica de células seja mais precisa por avaliar um maior número de células, esta pode induzir a um elevado número de falso-positivos que devem ser confirmados pela microscopia, para garantia de um resultado reprodutível. Cabe ressaltar que a análise da distensão após concentração de leucócitos aumentou a sensibilidade das contagens em aproximadamente $100 \%$ (de 9,6\% para $20,1 \%$ de concordância). ${ }^{5-7}$

Os resultados obtidos neste estudo permitem concluir que a automação é indispensável no laboratório de análises clínicas, fornecendo resultados sensíveis, reprodutíveis e precisos para alterações quantitativas. No entanto, as técnicas manuais, particularmente de concentrado de leucócitos, mostram-se insubstituíveis para alterações qualitativas e continuam úteis na rotina laboratorial, pelo fato de que algumas alterações hematológicas só podem ser diferenciadas pela microscopia.

\section{Abstract}

Leukopenia can be associated with the suppression of the bone marrow by drugs, malignant disease, systemic lupus erythematosus, infections, and agranulocytosis. However some patients without apparent disease have leukocyte counts of less than $4.0 \times 10^{9} / \mathrm{L}$. The difficulty in differential counting is related to the need of results that are reliable enough for correct clinical interventions. The aim of this study was to compare the results of differential white blood cell counts of leukopenia patients using different methodologies: electronic counting of cells utilizing the principle of impedance analysis and laser dissemination (Cell Dyn 3000), direct count under the microscope of 200 cells in both whole blood and the leukocyte layer (Buffy coat). Eighty-four samples of blood whit leukocyte counts of less than $4.0 \times 10^{9} / \mathrm{L}$ were analyzed. The results of this study showed that by comparing the different leukocyte count methods, both direct and with automation, neutrophils and lymphocytes showed good correlations (above 95\%), eosinophils, basophils and monocytes showed low correlation, and basophils, for at least two of the four groups examined, showed a statistically significant difference $(p<0.05)$. These data suggest that despite of automation providing more accurate and sensitive results, the technique of analyzing concentrated white blood cells in leukopenia patients can greatly contribute to confirm electronic count flags and in the identification of false-positive results. Rev. Bras. Hematol. Hemoter. 2009; 31(3):203-205.

Key words: Leukopenia; hematologic analyzers; optical microscopy; concentrate white blood cells. 


\section{Referências Bibliográficas}

1. Lee RG, et al. Wintrobe: Hematologia clínica; trad. Aparecida Marilda Peroco et al. São Paulo: Manole, 1998.

2. Lacaz CS, Machado CM. Oportunismo microbiano e de neoplasias na medicina contemporânea. São Paulo: Fundo Editorial BYK, 2000.

3. Zago MA, Falcao RP, Pasquini R. Hematologia: fundamentos e prática. 1. ed. São Paulo: Editora Atheneu, 2004.

4. Failace R. Hemograma: manual de interpretação. 4. ed. Porto Alegre: Artmed, 2003.

5. Bain BJ. Células sangüíneas: um guia prático; trad. Renato Failace. 4. ed. Porto Alegre: Artmed, 2007.

6. Failace R, Pranke P. Avaliação dos critérios de liberação direta dos resultados de hemogramas através de contadores eletrônicos. Rev. Bras. Hematol. Hemoter. 2004;26(3);159-66.

7. Ferreira AW, Avila, SL. M. Diagnóstico Laboratorial das Principais Doenças Infecciosas e Auto-Imunes. 2. ed. Rio de Janeiro: Guanabara Koogan, 2001.

Avaliação: Editor e dois revisores externos

Conflito de interesse: não declarado

Recebido: 19/11/2008

Aceito após modificações: 02/03/2009

Universidade de Passo Fundo - Instituto de Ciências Biológicas Passo Fundo-RS

Correspondência: Alessandra Patrícia Santos

Rua Alexandre da Motta, 585 - apto 603, Bairro Centro

99500-000 - Carazinho-RS - Brasil

Tel.: (55 54) 9132-7278

E-mail:lekafar@yahoo.com.br 